or not. Prof. Capellini, of whom I asked the question at the meeting of the British Association at Manchester, could not answer me. Frimâ facie we should certainly expect the Italian evidence to support the French, but this is by no means the conclusion to be drawn from text-books, in which it is generally taken for granted that in Italy the elephant and mastodon have been found at the same horizon.

The question is one of very great interest and importance, and an answer to it would be especially valuable to me. Perhaps some of your readers may have the means of answering it.

2I Earl's Court Square, February 28. HENRY H. HOWORTH.

\section{True Average of Observations?}

I HAVE long been dissatisfied with the method of taking the arithmetic mean as the most probable value of a comparatively few direct observations of a quantity. This is certainly the legitimate result of the theory of probability, or " method of least squares," when one knows nothing to guide one in giving more weight to one than to another observation.

But without knowing anything of the conditions under which the observations were made, or, otherwise, no choice among them being possible by considering these conditions, still, when one comes to compare the results among themselves, this comparison seems to me to afford means of judging between them. Thus, if all the results are plotted on sectional paper, they are found to be grouped closely together at one place and to be scattered wide apart at others. Now the most probable result (whatever be the right method of finding it) lies certainly somewhere about the place of close grouping; and it seems fair to consider those results that come near this place as the better ones, and to allow to them more weight than to the others in calculating the mean.

If the observations were extremely numerous, there can be no objection to taking the arithmetic mean as the true probable value. But one has usually to content one's self with a few only, and in order to get a better approximation in this case I have constructed the following formula. I would be glad if some of your correspondents will express their opinions as to its legitimacy. In a case of this kind one ought not to trust entirely to one's own judgment ; one should submit one's own judgment to be checked by that of several others.

The method I propose is as follows.

First fix upper and lower limits outside which the true value cannot possibly lie, and reject absolutely all measurements outside these limits. The result will not be appreciably affected by taking these limits a little higher or lower, and it is better to err in taking them too wide apart than vice versâ. One usually has, or ought to have, a general notion of the quantity sought for, sufficient to determine these limits; but if this be not so, they may be determined by adding to and substracting from the arithmetic mean what is thought to be the maximum possible error.

Let $x_{1}, x_{2}, x_{3}, \& \mathrm{c}$, be the excesses of the various measurements above the lower of the above possible limits. Let $x_{0}$ be the excess above the same limit of the as yet unknown most probable value as determined by the formula below.

Attach to cach $x$ the weight $\left\{\mathrm{I}-\left(\frac{x-x_{0}}{x_{0}}\right)^{2}\right\}$, and take as $x_{0}$ the mean of the $x$ 's with these weights attached.

Note that equal weights are given t') measurements equally above and below $x_{0}$. Also to an $x$ coinciding with the lower possible limit, a weight zero is given. Zero weight is also given to an $x$ as much above $x_{0}$ as the lower possible limit is below it.

The rule results in the following formula :-

$$
\begin{aligned}
\text { Weight for } x & =\mathrm{I}-\left(\frac{x-x_{0}}{x_{0}}\right)^{2}=\frac{2 x_{0} x-x^{2}}{x_{0}{ }^{2}}, \\
x & \times \text { weight }=\frac{2 x_{0} x^{2}-x^{3}}{x_{0}{ }^{2}} .
\end{aligned}
$$

Therefore, the mean equals-

$$
x_{v}=\frac{2 x_{0} \Sigma x^{2}-\Sigma x^{3}}{2 x_{0} \Sigma x-\Sigma x^{2}} .
$$

This is a quadratic for $x_{0}$, the solution of which is -

$$
x_{0}=\frac{3}{4} \frac{\Sigma x^{2}}{\Sigma x}\left\{\mathrm{I}+\sqrt{\mathrm{I}-\frac{8}{9} \frac{\Sigma x \Sigma x^{3}}{\left(\Sigma x^{2}\right)^{2}}}\right\} .
$$

Of course the labour of finding this mean is greater than that of finding the arithmetic mean; it involves summing the first, second, and third powers. But the method is only intended to be used when the number of values to be dealt with is not large, and with the help of a table of squares, cubes, and square roots, the work is not really very laborious.

It is easy to prove that this result is identical with the arithmetic mean in the following three cases: $(x)$ all the $x$ 's equal (2) the $x$ 's all equidistant, i.e. forming an arithmetic progression; (3) the $x$ s infinitely numerous.

\begin{tabular}{|c|c|c|c|c|c|c|c|c|c|c|}
\hline$x\{$ & $\begin{array}{c}{ }^{\circ} \text { or } \\
\\
I \cdot I\end{array}$ & $\begin{array}{r}\cdot 8 \\
\mathbf{I} \cdot 2\end{array}$ & $\begin{array}{r}7 \\
\times 3\end{array}$ & $\begin{array}{r}6 \\
\text { I. } 4\end{array}$ & & $\begin{array}{r}4 \\
\times 6\end{array}$ & & $\begin{array}{r}\cdot 2 \\
1.8\end{array}$ & $\begin{array}{r}\cdot \mathrm{I} \\
\mathrm{I} \cdot 9\end{array}$ & 2 \\
\hline $\mathbf{I}-\left(\frac{x-x_{0}}{x_{0}}\right)^{2}$ & I 99 & •96 & $9 \mathrm{I}$ & .84 & 75 & $\cdot 64$ & 51 & 36 & 19 & 0 \\
\hline
\end{tabular}

The practical meaning of the rule may perhaps be made clearer by the annexed table, giving the weights attachable to various values of $x$ where $x_{0}$ is taken equal to unity.

The following is a numerical example :-

$$
\begin{aligned}
& \begin{array}{rl} 
& x \\
r & 73 \\
\cdot 89
\end{array} \\
& x^{2} \\
& 2 * 993 \\
& 792 \\
& .776
\end{aligned}
$$

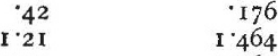

$$
\begin{aligned}
& \text { I.7715 } \\
& \Sigma x=\overline{5.42} \quad \Sigma x^{2}=\overline{6.794} \quad \mathbf{\Sigma} x^{3}=\overline{9.330} \\
& \sqrt{1-\frac{8}{9} \frac{\Sigma x \Sigma x^{3}}{\left(\Sigma x^{3}\right)^{2}}}=\cdot 162 \text { and } x_{0}=I^{\circ} 0925 \text {. }
\end{aligned}
$$

The arithmetic mean or $\frac{\Sigma x}{5}=1.084$.

Mason College, February 4.

ROBERT H. SMITH.

\section{Crepuscular Rays in China.}

IMMEDIATELY after sunset enormous rays of light are frequently seen spreading from the part of the horizon where the sun has disappeared, and also-though somewhat fainter-from the opposite part of the horizon. Sometimes the rays stret ch right across the sky, and when strongly developed they appear first in the east, and then in the west, and resemble auroral rays, glowing in a yellow or red colour, while the sky between the rays is deep blue or greenish. They appear to be caused by invisible cirro-stratus clouds high up in the air. This phenomenon is never seen in England, or at any rate it is by no means so conspicuous as here. Ancient Greek mariners may have had their imagination impressed by a similar phenomenon, fooso-

\begin{tabular}{|c|c|c|c|c|c|c|c|}
\hline 1885 & May. & June. & $\begin{array}{c}\text { July. } \\
3\end{array}$ & $\underset{2}{\text { Aug. }}$ & $\begin{array}{c}\text { Sept. } \\
4\end{array}$ & $\begin{array}{c}\text { Oct. } \\
3\end{array}$ & Nov. \\
\hline 1886 & - & I & I & I & 3 & 7 & - \\
\hline 1887 & I & - & - & 2 & 3 & - & - \\
\hline Mean & 0.3 & 0.3 & I. 3 & I 7 & $3 \cdot 3$ & 3 & 0.0 \\
\hline
\end{tabular}
$\delta \alpha ́ \kappa \tau \hat{v} \lambda$ os $\dot{\eta} \omega$ s being so frequently mentioned in Homer.

Crepuscular rays at sunrise or sunset are seen at all seasons in Southern China, but they are most frequent at the height of the typhoon season, and most intense just before typhoons, which latter are indicated beforehand by crepuscular rays as well as by halos.

The following table exhibits the number of evenings when strong crepuscular rays were registered in each month of the past three years, and also the mean monthly frequency of the strongly developed phenomenon :-

Hong Kong Observatory, December 3I, 1887 .

\section{"An Unusual Rainbow,"}

I READ with interest a letter with the above heading in Nature (vol. xxxvi. p. 581) from Mr. S. A. Hill of Allahabad, India, of date September 18,1887 . He describes a brilliant rainbow which he saw after the sun had set, and states that such a phenomenon "must be of rare occurrence," and that he had "never before seen anything similar, nor read anywhere a description of a rainbow after sunset." I had not read his letter when, on the 